\title{
19
}

\section{Faculty Quality of Life}

\author{
Sally S. Atkins
}

Kathleen T. Brinko

Jeffrey A. Butts

Charles S. Claxton

Glenda T. Hubbard

Appalachian State University

An interdisciplinary research team conducted a formal assessment of campus culture and faculty quality of life at Appalachian State University. Interviews with a stratified random sample of full-time, tenure-track faculty revealed five themes: 1) the importance of human relationships, 2) the deep commitment of faculty to student learning, 3) general satisfaction with academic life, 4) the personal sacrifice of faculty members for their work, and 5) perceptions of incongruence beiween institutional rhetoric and action. Recommendations are offered for readers to apply to their own universities to help faculty, staff, students, and administrators work together toward becoming an institution that is a true community of learners.

\section{INTRODUCTION}

any of the difficult issues facing higher education today involve the Verosion of some key values of faculty life: commitment to students, collegiality, intellectual integrity, professional autonomy, an ethic of public service, and a sense of connectedness to the mission of the institution. External demands for accountability, loss of public trust, and financial constraints have placed pressures on academic institutions. For faculty members, these pressures-along with decreasing mobility, increasingly stringent requirements for promotion and tenure, multiple role expectations, mandates for post-tenure review, and erosion faculty governance-have a great impact on faculty satisfaction, self-esteem, and 
quality of life (Austin, Brocato, \& Rohrer, 1997; Bowen \& Schuster, 1986; Rice \& Austin, 1988; Smith, 1990). Because of the central role of the faculty in the work of the academy-especially their influence on students - faculty vitality and well being are crucial. In our quest for greater accountability and productivity, it is imperative that we recognize the critical importance of promoting professional and personal growth for faculty.

\section{Faculty Quality of Life at Appalachian}

Appalachian State University is a comprehensive university of approximately 12,500 students, and one of the 16 institutions that comprise the University of North Carolina system. Because teaching excellence is our primary mission, and because strong faculty-student relationships are our tradition, faculty quality of life is an important priority at Appalachian. The present study is part of a long-term effort of the university to understand and address issues of individual and collective well being and organizational effectiveness. Over a period of 14 years the university has systematically studied the quality of life of several groups, including faculty (Hageseth \& Atkins, 1988), staff (Hageseth \& Atkins, 1989), new faculty (Branch, 1995), and chairpersons (Atkins \& Hageseth, 1991). The university has also engaged in an ongoing examination of the philosophical underpinnings of faculty and staff well being (Hubbard \& Atkins, 1995; Hubbard, Atkins, \& Brinko, 1998; van der Bogert, Brinko, Atkins, \& Arnold, 1990). These studies have influenced a number of programmatic and structural changes at Appalachian.

\section{KeY INFLUENCES ON OUR WORK}

Our ongoing efforts in reflective organizational change have been influenced by a number of current thinkers in higher education and organizational development. One stream of research that has greatly contributed to our thinking is Peter Senge's (1990) work on the learning organization. Senge sees learning organizations as places "where people continually expand their capacity to create the results they truly desire, where new and expansive patterns of thinking are nurtured, where collective aspiration is set free, and where people are continually learning how to learn together" (1990, p. 3). In Senge's model, members of a group work toward becoming a learning organization by practicing five disciplines: 1) personal mastery (intentionally learning and growing), 2) 
team learning (helping one another learn and grow), 3) mental models (uncovering deeply ingrained assumptions), 4) shared vision (working toward a collective purpose), and 5) systems thinking (understanding the whole as a system of interrelated, interacting parts).

Additionally, our thinking and our process are greatly indebted to Parker Palmer's $(1992,1997,1998)$ ideas on community and epistemology, Robert Kegan's (1994) work on meaning making and stages of adult development, Nevitt Sanford's (1980) seminal thinking on faculty development, and Margaret Wheatley's (1992) conceptualization of self-organizing systems as applied to human organizations.

Our work builds on the research of numerous colleagues in faculty development who have focused on broad issues of faculty vitality and quality of life. Our themes echo many of those found in Robert Boice's (1991) studies of new faculty, Mary Deane Sorcinelli's (1992) studies of new junior faculty stress associated with the tenure process, Irene Karpiak's (1997) studies of midlife faculty, and Arthur Crawley's (1995) studies of senior faculty. Our work is also consistent with the findings of the most recent survey of faculty members at 38 colleges and universities (Magner, 1999).

\section{MethodS}

Our research team was interdisciplinary in nature and consisted of three faculty members and two administrators working under the auspices of the Hubbard Center for Faculty and Staff Support. Our disciplinary backgrounds included biology, faculty and instructional development, higher education, psychotherapy, and counseling and human development. The chairperson of the Institutional Review Board approved the study, assuring that it conformed to the regulations stated in Appalachian State University's Policy and Procedures on Human Subjects Research.

\section{Instrument}

The 90-minute structured interview protocol was partially based on the instrument used in the previous study of faculty (Hageseth \& Atkins, 1988). The instrument also included some items from a staff quality of life survey that was being conducted simultaneously at Appalachian (Langdon, in preparation) and additional questions based on Senge's (1990) five disciplines. The instrument addressed three general areas of faculty perceptions: individual quality of life, organizational culture, and mission and vision (see Appendix 19.1). 


\section{Sample}

Subjects consisted of a stratified random sample of full-time, tenure-track faculty members. The Office of Institutional Research and Planning generated a list of all full-time, tenure-track faculty members sorted by department, with the order of faculty names randomized within departments. We selected ten percent from each department, contacting each person by phone to secure his/her assent for participation in the study. Similarly, in departments that had 14 or fewer full-time, tenure-track faculty, the first person on each departmental list was contacted. Likewise, in departments that had between 15 and 24 full-time, tenure-track faculty, the first and second persons were contacted, and so forth. If a selected faculty member was serving in an administrative role (such as chair or assistant dean), he or she was excluded from the study, and the next faculty member on the list was contacted. If a faculty member declined to participate (one individual) or was unavailable (two individuals), the next person on the list was substituted.

The subjects reflected the demographic parameters of our institution: The mean age was 49.2 , the average number of years at the university was 13.1 , and $29 \%$ of the sample were women. The sample included 24 full professors, ten associate professors, and 14 assistant professors. The identity of the subjects and their individual comments were kept confidential. After constructing a draft of the instrument and securing Institutional Review Board approval, we reviewed the purposes and methods of qualitative research and the procedures for structured interviewing (Bernard, 1995; Ely, 1991). We then conducted a pilot study of selected upper-level administrators (the chancellor and the four vice chancellors) to hone the interview questionnaire, to practice our interviewing skills, and to inform these individuals of the exact nature of the study.

Individual subjects were interviewed by a pair of interviewers (one male and one female) randomly assigned from our research team. Both members of the interviewing pair hand-recorded or keyboarded responses during each interview and compared notes immediately after the interview. During the interview, the two sought to create an atmosphere of empathy and respect and attended to nonverbal and verbal cues. While the interview questionnaire served as a guide for thorough and systematic collection of all data relative to the topics studied, we sought to go beyond mere descriptions of events and opinion to understand respondents' meanings in relation to the topics. We focused on understanding how each person was constructing her or his experience at Appalachian. 
After all interviews were completed, the entire research team by consensus analyzed and tabulated responses to each question. We attempted to honor each interviewee's specific words as well as the research team's collective discernment of meaning. By consensus we developed categories from the responses themselves. Both the frequency of specific categories of responses and the emergence of general themes were considered in the analysis. The type of question, the content of the response, and the context of the response helped us determine which themes were most important.

\section{Results}

In the process of analyzing the data, we found that faculty responses to the different questions clustered into several categories. The research team reviewed each category of response for each question and by consensus grouped the categories into themes. In reporting the findings of this study, we wish to highlight the five themes that emerged and to explore the relationship of the themes with each other. A copy of the detailed results analyzed question by question is available from the authors. (see http://www.hubbard.appstate.edu/od/qols.html)

\section{Theme \# 1: The Centrality of Relationships}

The most important factor in faculty quality of life is the quality of interpersonal relationships. For faculty, relationships with students are a high priority, a source of deep satisfaction, and a crucial aspect of creating an environment for learning. The images faculty use to describe their work, their sources of satisfaction, and their best experiences involve collegial relationships with students. However, many faculty feel increasingly less able to allocate time for such relationships. One subject stated, "We need to make sure that people with power understand that the essence of teaching is in relationships, and relationships take time." Relationships with colleagues are another important element of faculty life, one that can be deeply rewarding or profoundly hurtful. One subject echoed the sentiment of many when referring to positive relationships with colleagues: "The greatest satisfaction in my work environment has been the people I've worked with over the years." Another said, "I cherish their contribution to my growth." We also heard stories about negative collegial relationships: "I'd like a less rancid, hostile, negative, mean atmosphere in my department." Many faculty say the next step in their personal growth is to improve relationships, and many believe the university 
needs to strive to create an environment of community, with more mutual respect, civility, and dialogue among faculty, staff, students, and administrators. As one faculty member said,

"If scientists only talk to scientists, then the scientific method is the only way to get anything done. If historians only talk to historians, then bistory is the only reality. Not knowing each other is destructive to the community as a whole. It allows us to build up images of each other based on half-truths. We need each other desperately."

Relationships with family and friends also play an important role in faculty quality of life. Family responsibilities and personal relationships are regarded both positively-as supporting and enhancing professional work. For example, one subject said, "I have a very supportive husband. He appreciates what I do and goes out of his way to help me pursue professional opportunities important to me." The flip side, however, is that the demands of personal responsibilities can increase the amount of stress faculty feel in their professional work. One interviewee said,

"My parents are both in their 70s. They have enough money, but are unable to keep their affairs in order. Dad [is disabled] and Mom is recovering from cancer. It is a strain to be bere and have them live in lanother state]."

\section{Theme \#2: Commitment to Student Learning}

Most faculty members are deeply committed to providing meaningful and life-changing learning experiences for students. They often see their work as a calling, requiring strong commitment and sense of purpose. One subject stated, "I put students ahead of other things. This is a service profession. It is a privilege." Faculty members believe their primary mission is to foster student learning and to help students become lifelong learners and good citizens with appropriate values and interpersonal skills. As one interviewee said, "I want to impart to my students an excitement for learning and an excitement about their field. I want to give them marketable skills. I want them to have strong problem solving skills and a sense of ethics." Further, Appalachian faculty envision education as a process that is much deeper and more transforming than job training. One subject stated, "I'm concerned about students being prepared to write and speak, not just for a good job, but for a good life." Another said, "One place where colleges have gotten in trouble is seeing themselves as training schools. College should be about opening minds and eyes." Fac- 
ulty believe that maintaining and improving the quality of the educational experience offered to students should be a high priority for future changes in the university. One subject observed, "Educating for the next century is the most important thing."

With the goal of enhancing the quality of educational opportunities for students, many faculty believe we need to limit enrollment and to increase resources for departments and the library. One subject expressed concern for shrinking resources: "I'm troubled when I hear people talk about delivering instruction more efficiently in larger classes. I don't deliver instruction." Faculty desire changes that will enable them to spend more time with students, such as reduced number of classes, reduced class sizes, less paperwork, and fewer committee assignments. As one faculty eloquently stated, "I'd like to teach less so I can teach better."

Appalachian faculty are also troubled by the pressures for accountability, not because they are afraid to be found out as poor teachers, but because they fear that inappropriate measures may be used. For example, one said, "Education is valuable, and the most valuable aspects are difficult to measure. Our product is not like soybeans." Another expressed a concomitant concern: "So much of what we do doesn't count on paper."

\section{Theme \#3: Satisfaction with Academic Life}

Regarding general satisfaction with academic life, our findings correlate with a recent study (Sanderson, Phua, \& Herda, 2000) showing that $90 \%$ of American faculty find deep satisfaction in "the academic life." Most enjoy learning in their field and delight in sharing that joy of learning with others. One interviewee articulated the sentiment of many: "I feel fortunate to be in a profession in which I really like what I'm doing." Professional satisfaction in academic life is also related to a number of other factors, such as professional autonomy, self-direction, and opportunities for further professional growth and learning. One subject said, "The university is a central part of my life. I have always felt supported, recognized, and free to go in the directions important to me." Many find deep satisfaction in making an important contribution to the lives of students, the discipline, and society. As one interviewee said, "My status in the field is less important to me than my influence on students."

\section{Theme \#4: Personal Sacrifice}

The large majority of faculty members believe the professorial workload is difficult - if not impossible-without making very costly personal sacrifices. As noted previously (Sanderson, Phua, \& Herda, 2000; Karpiak, 
1997; Sorcinelli, 1992) most find it very difficult to balance their professional workload of teaching, scholarship, and service effectively, and they find it almost impossible to balance their personal and professional lives. One faculty member said, "My personal life gets put on hold so that I can balance the professional. It gets put on hold a lot." Another observed, "Last weekend I had one and one-half hours-that was my personal life last week." In deciding which area to sacrifice, most choose to devote more time to the profession and their students at the expense of family and personal life. One interviewee lamented, "I wish I had more time for family." Another subject recounted, "My wife and I are separated; my workaholism probably caused the separation. It is difficult to balance. I am trying hard to make my family my first priority, but my workload interferes."

Others say that their lives are somewhat balanced, but their descriptions suggest that they simply accept the assumption that their personal life must be sacrificed. One subject observed, "Work just eats up your life." Previous studies have noted the perceived demands of faculty life as contributing to the potential for faculty "burn out" (Bowen \& Schuster, 1985; Freedman, 1986; Jacobson, 1984; Schuster \& Bowen, 1985; Karpiak, 1997; Altbach \& Lewis, 1995). Of the few who feel that they are able to balance the demands of both their personal and professional lives, most do so by combining the two, such as by working side-by-side on projects with a spouse who is also a faculty member. Others mentioned socializing with colleagues. For example, one subject observed, "My work life overlaps with my personal life. Many of the same people I see socially I see on committees."

\section{Theme \#5: Incongruence between Rhetoric and Action}

Some faculty question the integrity of institutional rhetoric and leadership, doubting the effectiveness and honesty of administrators, a phenomenon also noted by Altbach and Lewis (1995) in an international study of faculty attitudes. Some appear to mistrust administrators in general, with the intensity of distrust generally stronger at the dean and upper levels of administration. One example is that the stated mission of Appalachian places primary emphasis on teaching and learning. One faculty member stated, "The emphasis on teaching does not reduce the expectations of the traditional things. I get irritated with the mixed messages." Another said, "I think the administration needs to sit down and decide what the mission is and go after it. They can't have one department or college going one way and another going another. We need con- 
sistency and continuity." Many faculty see the mission as changing or unclear. For example, one subject said, "I don't know if I know what our university really does; we're not actually doing anything to help the area or the nation; the stuff from administrators is money and 'cover your ass,' not vision." Others believe the institution is hypocritical, with actual policies, procedures, and budget allocations reflecting a mission quite different from the stated mission. One subject captured a common sentiment: "People look at what is really rewarded, not what the administration says is rewarded." Another faculty member wished for a change in our collective perspective: "We should recapture a vision where administrators see themselves as serving faculty and staff, to enable faculty and staff to serve students."

Other faculty also worry about an increasing lack of substance, meaning, and integrity. One subject said, "We need less stress on procedure and more on substance. A common joke about Appalachian is that it seems to emphasize procedure over substance. It's a public relations approach now." Another stated the sentiment more positively: "We're trying to grow horizontally, more people, more buildings, etc. It's time to grow by deepening our definition of identity and purpose."

\section{Discussion}

The stories of the 48 individuals interviewed in this project give us meaningful information about current faculty life and the climate of the university. The findings of the present study reaffirm those of other recent studies in noting the strong commitment of faculty to their work, the general satisfaction with academic life (Sanderson, Phua, \& Herda, 2000; Sorcinelli, 1992), and the critical importance of relationships in faculty perceptions of quality of life (Gablenik, 1997; Karpiak, 1997; Palmer, 1997). Among these diverse faculty members, there is a strong sense of responsibility and a high level of professionalism despite their dissatisfactions, frustrations, and disappointments. There is also a yearning, individually and collectively, for real human community with colleagues and with students, and for learning that goes beyond the superficial-learning that is deepening and life-changing for themselves and their students. Faculty morale varies greatly from department to department; some departments are characterized by a sense of mutuality with colleagues and administrators. In contrast, other departments have a toxic environment that withholds support and undermines emotional and professional growth. As noted in previous studies (Massy \& Wilger, 1995; Atkins \& 
Hageseth, 1991; Hagaseth \& Atkins, 1988), the department chairperson plays a critical role in setting the cultural tone of the department.

Many critics of higher education argue that the professoriate is not committed to teaching. State legislatures, boards of trustees, and accrediting agencies now insist on accountability and assessment of outcomes in ways never experienced by higher education before. Within institutions themselves, many faculty feel attacked and see a loss of public esteem that in the past was one of the intangible rewards for academic life. However, examination of the five themes emerging from the data convinces us that the faculty interviewed in this study are unselfishly committed to influencing their students and the world in positive ways, with little thought of personal gain.

\section{INTERRELATIONSHIPS AMONG THE FIVE TheMES: A Systems Perspective}

Peter Senge (1990) suggests that the problems facing organizations are in direct proportion to our ability —or inability - to see the organization as a whole. Senge's notion of systems thinking is a framework for seeing interrelationships rather than individual parts and can help us become aware of the subtle interconnections among apparently disparate pieces. Thus, systems thinking helps us to examine the five themes not as isolated pieces but as different strands of a larger whole. Previously, we articulated the themes separately, but we acknowledge that the separation is artificial. Each theme is intertwined with all the others, affecting each of them and in turn being affected by them. Figure 19.1 suggests a way to think about these interrelationships.

In our examination of the five major themes, it is clear that one, the centrality of relationships, is the matrix holding and shaping the faculty member's expression of the other themes. The quality of the relationships - whether positive or negative-with students, colleagues, administrators, and family appears to function as a lens which focuses the expression of the other themes and acts to reduce or exacerbate the tension between themes. Thus in our visual model, the circle of relationships encompasses and surrounds the circles representing the other themes.

While we recognize there are interactions and potential tensions among all of the themes, there is a dialectical tension between the theme of satisfaction with academic life and the theme of personal sacrifice, and between the theme of commitment to student learning and the theme of incongruity between rhetoric and action. For that reason, we have placed 
FIGURE 19.1

The Interrelationship among the Five Themes

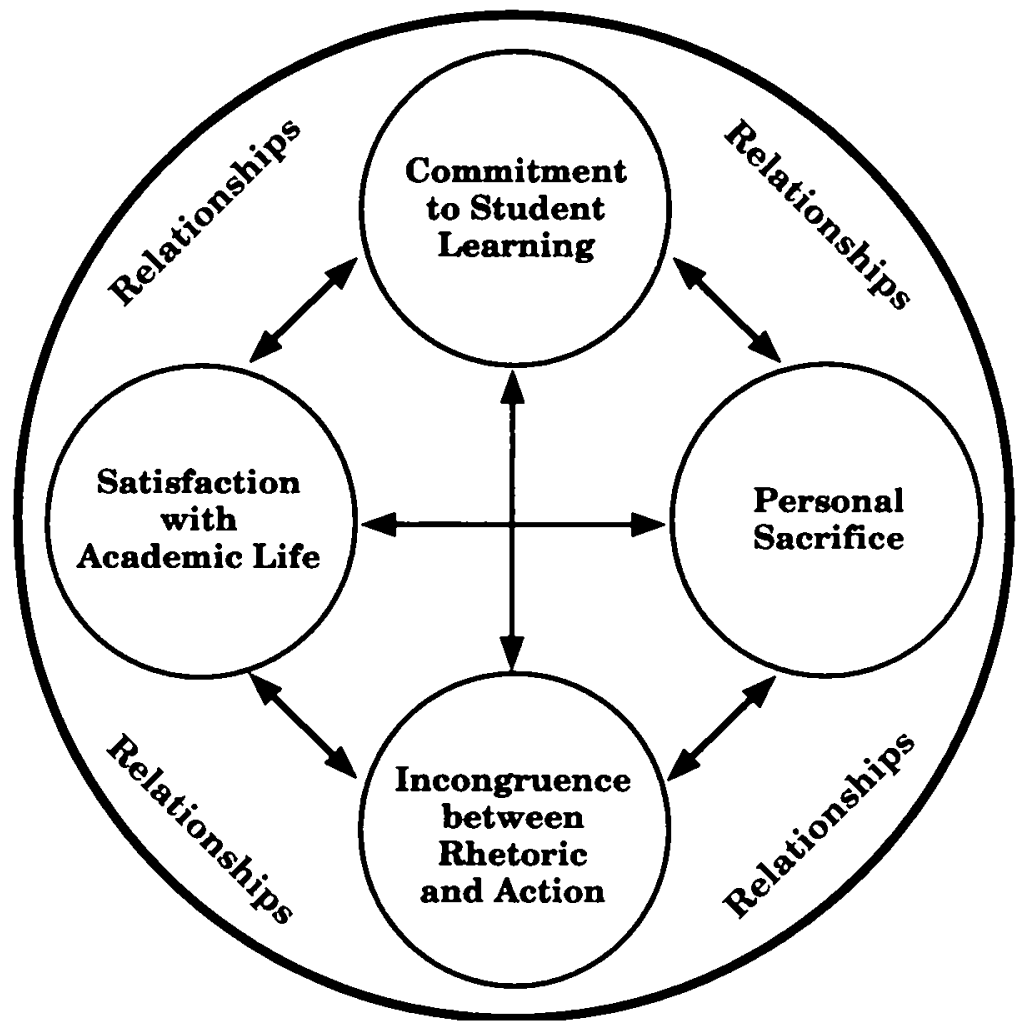

the circles representing those themes as polar opposites upon the background of the theme of the centrality of relationships. At first it would appear that the faculty members' reported satisfaction with academic life is diametrically opposed to the high level of personal sacrifice involved in accomplishing the myriad tasks of faculty work. However, if the quality of relationships between the faculty member and his/her colleagues and students is high and rewarding, the potential opposition of the intense demands of faculty life is ameliorated, and personal sacrifice becomes an accepted aspect of faculty life. Similarly, it seems contradictory that many faculty members perceive an incongruity between institutional rhetoric and action while simultaneously having a high level of commitment to student learning. However, if the quality of relationships between the faculty member and students is positive, the faculty member 
is more willing to accept and tolerate a perceived incongruity between rhetoric and action. Conversely, if the relationships between the faculty member and students are negative, the tension and dissatisfaction with perceived institutional incongruities are heightened.

Tensions between other pairings of themes and the interaction between those themes and the milieu of relationships, while more subtle, are as intricate and fluid as those discussed previously. For example, the degree of personal sacrifice involved in faculty life would, at first glance, appear to act to dampen a faculty member's deep commitment to student learning since such commitment may entail more time demands, and thus more personal sacrifice. Nonetheless, positive relationships with students can reinforce the faculty member's commitment to student learning and lessen the perceived emotional and personal cost of the personal sacrifices.

In a like manner, positive personal relationships between the faculty member and department chairs, deans, and other administrators can reduce the psychological importance of perceived incongruence between institutional rhetoric and actions. Those positive personal relationships will also tend to increase faculty members' general satisfaction with academic life and their willingness to accept personal sacrifice as a part of life in academe. On the other hand, unpleasant relationships or conflicts between faculty and administrators can heighten the importance of perceived incongruence between rhetoric and action and result in a negative feedback loop, diminishing both satisfaction with academic life and the palatability of personal sacrifice.

A high level of satisfaction with academic life-due in part or in whole to supportive and positive relationships with students, colleagues, and administrators-can increase a faculty member's commitment to student learning. Conversely, difficult relationships with students and colleagues can decrease general satisfaction with academic life and have a concomitant impact on commitment to student learning.

We must reemphasize that all five themes are interconnected and interrelated. The level of satisfaction with academic life is influenced and shaped by the quality of all interpersonal relationships within the sphere of the university community; and the satisfaction with academic life in turn helps to mold the level of commitment to student learning, the acceptability of personal sacrifice, and the perception of incongruence between institutional rhetoric and action. While we recognize that our proposed model is imperfect-as are all models-it has helped us to understand the results and to formulate recommendations. 


\section{ReCOMmendations}

Several possible directions emerge from this research. Based upon careful consideration of the data, we offer readers the following recommendations. We hope the recommendations will be useful starting points for open conversations at our own university and perhaps at others regarding strategic planning, policy development, programming, resource allocation, and structural change. We hope these recommendations will help faculty, staff, students, and administrators work together toward fulfilling the university's mission and the university's goal of becoming a true community of learners.

\section{Recommendation \#1: Recognize and Honor the Centrality of Human Relationships}

- Support university, college, departmental, and unit efforts to become more effective working and learning communities involving faculty, staff, students, and administrators.

- Create opportunities for individual and collective learning focused on understanding leadership, group process, interpersonal dynamics, and self-reflection.

- Increase the skills of administrators, faculty, and faculty leaders in these arenas.

- Recognize the pivotal role of department chairpersons in the well being of the institution by providing support for chairperson professional growth and development.

- Provide increased assistance to chairpersons so that they have the time to fulfill their roles as faculty leaders.

- Support formal and informal activities that foster cross-disciplinary and cross-unit interaction.

- Encourage examination of problems and issues from multidimensional perspectives.

\section{Recommendation \#2: Support the Deep Commitments of Faculty to Foster Student Learning}

- Provide faculty with the clerical support, equipment, time, classrooms, and office space to do their jobs well. 
- Ensure that faculty reward systems recognize differing faculty contributions that promote student learning outside as well as inside the classroom.

- Redefine departmental values so they are consistent with the primary purpose and values of the university. Encourage academic departments to move toward a collective responsibility for teaching and learning.

Recommendation \#3: Preserve the Traditional Satisfactions of Academic Life for Faculty

- Preserve academic freedom and faculty autonomy-the hallmarks of academic life.

- Provide faculty with strong support for their continued professional and personal growth. Create opportunities for growth within the university, particularly activities that encourage interdisciplinary learning.

- Support and encourage scholarship in all its many forms. Define scholarship broadly, and embrace disciplinary differences in how scholarship is practiced.

\section{Recommendation \#4: Encourage Flexibility of Faculty Work and a More Balanced Life}

- Support faculty in maintaining quality work while keeping a well-balanced life. Encourage faculty to honor family priorities and spiritual needs, and to nurture physical and emotional well being.

- Respect and reward differing contributions made by individuals during the stages and seasons of academic professional life.

- Create ways to evaluate and reward the quality of work, rather than the quantity of work.

- Reward work that contributes to the good of the whole as a learning community.

- Reduce the increasing paperwork and the subtle pressures that support a culture of workaholism. 


\section{Recommendation \#5: Uphold the Integrity of the Academic Mission of the University}

- Encourage and support efforts for individual units and the university as a whole to be a learning community.

- Work toward a consensus regarding the university's mission, synthesizing the values of a liberal education, the values of applied professional programs, the stated institutional mission, the educational needs of today's students, and the deep commitment of faculty to student learning.

- Make all university decisions regarding resources, space, policies, procedures, and strategic planning consistent with the academic purposes of the university. Allocate resources based on the direct and indirect support of the academic mission.

- Clarify the mission of the university to students, faculty, staff, and administrators at every level of the university.

- Align the reward systems for faculty with the university mission.

- Streamline and make meaningful the annual report process. To encourage shared vision and shared responsibility, create a seamless process that holds individuals and units responsible for implementation of the principles of the mission statement and strategic plan.

- Create opportunities for individual and collective learning focused on understanding systems thinking.

- Open lines of communication across units and up and down the hierarchy.

\section{REFERENCES}

Altbach, P. G., \& Lewis, L. S. (1995). Professional attitudes-an international survey. Change, 27 (6), 51-58.

Appalachian State University. (1998). The strategic plan. Boone, NC: Appalachian State University.

Atkins, S. S., \& Hageseth, J. A. (1991). The academic chairperson: Leading faculty is like herding cats. Journal of Staff, Program, and Organizational Development, $9(1), 29-35$. 
Austin, A. A., Brocato, J. J., \& Rohrer, J. D. (1997). Institutional missions, multiple faculty roles: Implications for faculty development. In D. Dezure \& M. Kaplan (Eds.), To improve the academy, 16, 3-20. Stillwater, OK: New Forums.

Bernard, H. R. (1995). Research methods in antbropology. Walnut Creek, CA: Altamira.

Boice, R. (1991). New faculty as teachers. Journal of Higher Education, 62 (2), 150-173.

Bowen, H. R., \& Schuster, J. H. (1985). Outlook for the academic profession. Academe, 71 (5), 9-17.

Bowen, H. R., \& Schuster, J. H. (1986). American professors: A national resource imperiled. New York, NY: Oxford.

Branch, V. (1995). Teaching is "job number one": New faculty at a comprehensive university. Joumal of Staff, Program, and Organizational Development, 12, 209-218.

Crawley, A. L. (1995). Faculty development programs at research universities: Implications for senior faculty renewal. In E. Neal (Ed.), To improve the academy, 14, 65-90. Stillwater, OK: New Forums.

Ely, M. (1991). Doing qualitative research: Circles within circles. Bristol, PA: Falmer.

Freedman, J. (1986). The professor's life, though rarely clear to outsiders, has its rewards and costs. Chronicle of Higher Education, 31 (23): 92.

Gablenik, F. (1997 Jan/Feb). Educating a committed citizenry. Change, 29 (1), 30-35.

Jacobson, R. L. (1984). AAUP's leaders assays decline in faculty morale, governance. Chronicle of Higher Education, 27 (18), 15-17.

Hageseth, J. A., \& Atkins, S. S. (1988). Assessing faculty quality of life. In J. G. Kurfiss (Ed.), To improve the academy, 7, 109-120. Stillwater, OK: New Forums.

Hageseth, J. A., \& Atkins, S. S. (1989). Building university community: Where's the staff? Journal of Staff, Program, and Organizational Development, 7 (4), 173-180.

Hubbard, G. T., \& Atkins, S. S. (1995). The professor as a person: The role of faculty well-being in faculty development. Innovative Higher Education, 20, 117-128.

Hubbard, G. T., Atkins, S. S., \& Brinko, K. T. (1998). Holistic faculty develop- 
ment: Supporting personal, professional, and organizational well-being. In M. Kaplan \& D. Lieberman (Eds.), To improve the academy, 17, 35-49. Stillwater, OK: New Forums.

Karpiak, I. E. (1997). University professors at mid-life: Being a part of-but feeling apart. In D. Dezure \& M. Kaplan (Eds.), To improve the academy, 16, 21-40. Stillwater, OK: New Forums.

Kegan, R. (1994). In over our heads: The mental demands of modern life. Cambridge, MA: Harvard University Press.

Langdon, H. H. (in preparation). Staff quality of life study. Boone, NC: Appalachian State University.

Magner, D. K. (1999, September 3). The graying professorate. The Chronicle of Higher Education, A18-19.

Massy, W. F., \& Wilger, A. K. (1995). Improving productivity. Change, 27 (4), $10-21$.

Palmer, P. J. (1992). Divided no more: A movement approach to educational reform. Change, $24(2), 12-17$.

Palmer, P. J. (1997). The renewal of community in higher education. In W. E. Campbell \& K. A. Smith (Eds.), New paradigms for college teaching (pp. 1-18). Edina, MN: Interaction Book Co.

Palmer, P. J. (1998). The courage to teach: Exploring the inner landscape of a teacher's life. San Francisco, CA: Jossey-Bass.

Perry, W. G. $(1970,1999)$. Forms of intellectual and ethical development in the college years: A scheme. New York, NY: Holt, Rinehart \& Winston.

Rice, R. E., \& Austin, A. (1988). High faculty morale: What exemplary colleges do right. Change, 20(2), 50-58.

Sanderson, A., Phua, V. C., \& Herda, D. (2000). The American facully poll. Chicago, IL: National Opinion Research Center.

Sanford, N. (1980). Learning after college. Orinda, CA: Montaigne.

Schuster, J. H., \& Bowen, H.R. (1985). The faculty at risk. Change, 17 (4), 13-21.

Senge, P. M. (1990). The fifth discipline: The art and practice of the learning organization. New York, NY: Doubleday.

Sorcinelli, M. D. (1992). New and junior faculty stress: Research and responses. In M. D. Sorcinelli \& A. E. Austin (Eds.), Developing new and junior faculty (pp. 27-37). San Francisco, CA: Jossey-Bass. 
Smith, P. (1990). Killing the spirit: Higher education in America. New York, NY: Viking.

van der Bogert, V., Brinko, K. T., Atkins, S. S., \& Arnold, E. L. (1990). Transformational faculty development: Integrating the feminine and the masculine. In L. Hilsen. (Ed.), To improve the academy, 9, 89-98. Stillwater, OK: New Forums.

Wheatley, M. J. (1992). Leadership and the new science. San Francisco, CA: BerrettKoehler.

Contacts:

Sally S. Atkins

Professor, Human Development \& Psychological Counseling

Faculty/staff psychologist, The Hubbard Center

Appalachian State University

Boone, NC 286808

Email: Atkinsss@appstate.edu

Kate T. Brinko

Director, Faculty and Academic Development

Hubbard Center for Faculty and Staff Support

Appalachian State University

P.O. Box 32074

Boone, NC 28608-2074

(828) 262-6152

(828) 262-6159 (Fax)

Email: Brinkokt@appstate.edu

Jeffrey Butts

Director, Hubbard Center for Faculty and Staff Support

Appalachian State University

P.O. Box 32074

Boone, NC 28608-2074

Email: Buttsja@appstate.edu

Chuck Claxton

Professor Higher Education

Appalachian State University

Boone, NC 28608

(828) 262-2875

(828) 262-6035 (Fax)

Email:Claxtoncs@appstate.edu 
Sally Atkins coordinates the organizational development efforts of the Hubbard Center for Faculty and Staff Support at Appalachian. Recently this effort has included research on quality of life issues, chairperson development, administrative internships, and other initiatives for organizational change. She is a full-time faculty member, teaching courses in expressive arts therapy.

Kate Brinko has been Director of Faculty and Academic Development at Appalachian State University since 1988. As her career matures, she finds her interests moving from traditional faculty development efforts-working with individuals in a one contact, short-term, content-based activity-to working with groups in deeper, long-term, self-awareness and community-building efforts. Participating in this interdisciplinary research team researching faculty quality of life over a two-year period of time was one of her most professionally rewarding activities.

Jeffrey A. Butts has been Director of the Hubbard Center for Faculty and Staff Support at Appalachian State University since 1995. Previously he served as chairperson of the Department of Biology where he continues to teach general zoology, comparative anatomy, and vertebrate evolution.

Chuck Claxton is Professor in the Higher Education Program at Appalachian State University. He served on the faculty of the Summer Institute for the Management of Lifelong Education at Harvard University from 1986-1995. His major research interests are institutional change, adult development, and the learning organization. He and his family live in the small mountain town of Blowing Rock, NC.

Glenda Hubbard has been Director of Counseling for Faculty and Staff for four years, after serving as part-time counselor in the office while serving as a program coordinator and professor in counselor education for 25 years. After participating in the ASU Quality of Life research project, she is committed to the development of programs that improve the quality of life for faculty, staff, and students on the campus. 


\section{APPENDIX 19.1 \\ Appalachian State University \\ 1997 Faculty Quality of Life Study}

\section{Purpose}

By request of the provost, the Hubbard Center is conducting a follow-up study to the one done ten years ago. Its purpose is to ascertain the views of faculty about the organizational climate of Appalachian and the quality of faculty life as they see it. These findings will become the basis for recommendations to the Division of Academic Affairs.

\section{Confidentiality and Hand Recording}

1) The identity of all interviewees will be held in strict confidence. Information will be recorded by us and analyzed by the team of five interviewers. We have 20 questions, which take approximately one and one-half hours.

2) Are you willing to participate? Yes No

3) Do you have any questions before we begin? Yes No

\section{Demographic Data}

1) Department

2) Rank

3) Years at rank

4) Years at Appalachian

5) Gender

6) Age

7) Marital/Relationship Status

8) Do you have responsibility for the care or support of children? Please explain.

9) Do you have responsibility for the care or support of parents? Please explain.

NB: An asterisk denotes that this question appeared on the previous faculty quality of life survey. Italics denote that this question is drawn from Senge's five disciplines. 


\section{Quality of Life}

*1) On a scale of 1-10 (1 being the most negative, 10 being the most positive) rate your overall quality of life. Please comment on your rating. How does this compare with your quality of life ten years ago? (If person was here ten years ago.)

*2) a. What are the major factors that contribute to your satisfaction in your life?

b. What are the major factors that contribute to your dissatisfaction in your life?

*3) On a day-to-day basis, what in your work setting has the greatest impact on your morale?

4) a. How do you balance your professional responsibilities of teaching, research, and service?

b. How do you balance your professional and personal life?

*5) a. Describe your best experience working at Appalachian.

b. Describe your worst experience working at Appalachian.

6) How do you balance your individual/professional needs on the one hand, with your sense of collective responsibility, on the other hand?

*7) a. In your own development as a professional and as person, what is the next step in your professional growth?

b. What is the next step in your personal growth? (i.e., your growing edge; or What are the questions you are working on?) (personal mastery)

*8) Give a word or phrase that comes to mind when you hear each of the following words:

Health Spirituality Parents

Aging Retirement Children

Leisure

\section{Organizational Culture}

*9) Give us a word or phrase that comes to mind when you hear each of the following words: 


$\begin{array}{lll}\text { Appalachian } & \text { Committees } & \text { Dean } \\ \text { Teaching } & \text { Department } & \text { Administration } \\ \text { Scholarship } & \text { College } & \text { Students } \\ \text { Service } & \text { Chairperson } & \text { Colleagues }\end{array}$

10) a. On a scale of 1-10 (10 being most positive and being most negative), rank the climate of your department as to how well it supports the professional and personal growth of all of its members. Please comment on your rating. (learning organization)

b. Rank the climate of your college (school or administrative unit). Please comment on your rating. (learning organization)

c. Rank the climate of Appalachian. Please comment on your rating. (learning organization)

11) a. Think about the two or three persons in your department who are most respected. What qualities do they embody?

b. Think about the persons in your department who are least respected. What qualities do they embody?

12) a. Where in your work at Appalachian do you experience being part of a team effort?

b. What is this experience like for you? (team building)

\section{Mission/Vision}

13) At a very basic level, what is it you are trying to do in your work at Appalachian? (vision)

14) What in your view is the mission of Appalachian? (vision)

*15) How well does the mission of Appalachian fit with what you are trying to do? (vision)

16) What should we be trying to create at Appalachian in the future? (vision)

17) What particular changes would you like to see at Appalachian in the next ten years? (vision)

18) a. What do you think are the major issues facing Appalachian today? 
b. What do you think Appalachian should do to address these issues?

19) If you could change one thing that would have the most impact on your overall quality of life at Appalachian, what would that be?

20) In summary,

a. Would you share an image that describes Appalachian?

b. Would you share an image that describes your professional life here?

\section{Other Comments:}

(1) 1997, Atkins, S. S., Claxton, C. S., Brinko, K. T., Hubbard G. T., Butts, J. A. 